\title{
Structure and property of microinjection moulded poly (lactic acid) with high degree of long chain branching
}

Zhong-Guo Zhao, ${ }^{a}$ Qi Yang, ${ }^{*}, a$ Phil Coates, ${ }^{b}$ Ben Whiteside, ${ }^{b}$ Adrian Kelly, ${ }^{b}$ Ya-Jiang Huang, ${ }^{a}$ and Ping-Ping $\mathrm{Wu}^{a}$

${ }^{a}$ College of Polymer Science and Engineering, the State Key Laboratory for Polymer Materials Engineering, Sichuan University, 610065, Chengdu, PR China

bolymer IRC, Faculty of Engineering and Informatics, School of Engineering, University of Bradford, BD7 1DP, Bradford, UK

${ }^{*}$ Correspondence to Qi Yang. Email address: yangqi@scu.edu.cn. Tel.: + 08628 85401841; fax: + 086-28-85405402

Abstract: In this study, long chain branches (LCB) are successfully grafted to linear poly (lactic acid) (PLA) using functional group reactions with pentaerythritol triacrylate (PETA) and Tetraethyl thiuram disulfide (TETDS). Results show a high branching degree of PLA ( $\sim 49.5 \%$ ) can be effectively obtained with adding only $1 \mathrm{wt} \%$ of PETA, contributing remarkably to enhancing strain hardening. The density of the nuclei formed during non-isothermal crystallization for LCB-PLA samples is markedly increased contrasted with PLA, resulting in significantly enhancing crystallinity from $13.3 \%$ to $41 \%$, the onset crystallization temperature $\left(\sim 20^{\circ} \mathrm{C}\right)$, and the crystallization rate. Interestingly, compared with mini-injection moulding, the elevated wall shear rates (and corresponding shear stresses) prove to be beneficial to the creation of special crystalline morphologies ( $\beta$-crystal form) and oriented structures under microinjection moulding conditions, resulting in the improvement of tensile strength by $\sim 45 \mathrm{MPa}$.

KEYWORDS: Poly (lactic acid), chain branching, microinjection moulding, high crystallinity, mechanical properties

\section{Introduction}

In recent years, the demand for miniature and micro scale components has been increasing to satisfy the requirement for smaller, lighter devices with increased functionality. Microinjection moulding (MIM) has emerged as an ideal process to 
satisfy such demand by providing a route for high volume production at comparatively low cost. ${ }^{1}$ Moreover, relative to microinjection mouldings formed from metal or silicon materials, polymer microinjection mouldings have several merits, including low cost and high production efficiency. ${ }^{2}$ The availability of numerous medical grade thermoplastics has provided opportunities for creating a range of medical devices including implants and the study of MIM in polymer process engineering has become an attractive topic for creating miniature devices for healthcare applications. For instance, Chen et al. ${ }^{3}$ probed the influence of process parameters on the change in morphological structures in poly (lactic acid)/hydroxyapatite nanocomposites during the microinjection process. The extreme shear stress encountered by the material in the process promotes formation of an in-situ PLA fibrillar structure.

Much attention has recently focused on PLA due to desirable attributes including biodegradability and sustainable manufacturing. ${ }^{4-5}$ Therefore, PLA is being widely used for biomedical applications in the body for resorbable sutures, bone-fixation devices and sutures for microsurgery. ${ }^{6-8} \mathrm{~A}$ key factor is that it can undergo hydrolytic decomposition in the body, creating a harmless carbohydrate metabolic, and avoiding the need for surgical removal. However, commercially available linear PLA has comparatively low melt strength and crystallization properties that cannot satisfy the demands of practical applications. ${ }^{9-11}$ To expand the number of potential commercial and industrial applications, it is essential to improve performance in these areas by modifying the material.

Some methods have been proposed to improve the crystallization properties, including changing the composition of polylactide random copolymers, ${ }^{12-13}$ plasticization, ${ }^{14-15}$ and the addition of nucleating agents. ${ }^{16-17}$ Introducing long chain branches into PLA matrix has been used to improve the crystallization properties and melt strength. This is convenient and cheap, and can be used to produce materials at an industrial scale. ${ }^{18-19}$ In one example, a melt radical reaction was used to produce branched PLA by reacting with pyromellitic dianhydride (PMDA) and triglycidyl isocyanurate (TGIC). ${ }^{18}$ This showed that the melt strength could be improved (by about $3 \mathrm{MPa}$ ). You et al. ${ }^{20}$ observed that grafting pentaerythritol triacrylate (PETA) onto PLA resulted in improved crystallinity compared to neat PLA (about 11\%). However, the improvements in mechanical properties, the branched degree and the crystallinity were not sufficient to overcome key processing challenges, which undoubtedly limited its 
applications in the biomedical field. Considering these previous results, ${ }^{18-20}$ the current work aims to explore whether both crystallization properties and melt strength can be improved simultaneously by introducing long chain branched structures and controlling the processing phase to produce an optimized morphology. In our study, a two-step functional group reaction and the application of MIM have been further developed to realize this possibility. The MIM process has extremely high injection speeds (up to $\left.1200 \mathrm{~mm} \mathrm{~s}^{-1}\right)$ and maximum shear strain rate $\left(>10^{5} \mathrm{~s}^{-1}\right)$ and short filling times, which can significantly influence crystallization and the formation of oriented clusters. Furthermore, compared with conventional injection moulding, ${ }^{21}$ microinjection moulding is also widely used to investigate the complex flow-field induced morphology and structure changes of semi-crystalline polymers during practical processing. The investigation of microinjection moulded LCB-PLA systems is rarely reported in the literature to date.

In the present study, a versatile and efficient approach to obtain long chain branched PLA samples with superior tensile strength and crystallization ability is presented. Subsequently, LCB-PLA microinjection mouldings were prepared by microinjection moulding to systematically improve the tensile strength and crystalline properties. The effect of micromoulding processing conditions on the microstructures and properties of microinjection mouldings were systematically investigated. At the same time, miniinjection moulded samples were utilized to compare with the microinjection moulded samples.

\section{EXPERIMENTAL SECTION}

2.1 Materials. Poly (lactic acid) (PLA) used in this study was supplied by NatureWorks (4032D). The weight-average molecular weight and polydispersity were $2.1 \times 10^{5} \mathrm{~g} / \mathrm{mol}$ and 1.7 , respectively. The melting temperature of PLA measured by differential scanning calorimeter at $10{ }^{\circ} \mathrm{C} / \mathrm{min}$ is $167.2{ }^{\circ} \mathrm{C}$. Pentaerythritol triacrylate (PETA), Dicumyl peroxide (DCP) and Tetraethyl thiuram disulfide (TETDS) were all supplied from Sigma.

2.2 Sample preparation. The chemical reaction of the raw PLA with additives was prepared via an internal mixer (Haake Rheocord 90) at $180{ }^{\circ} \mathrm{C}$. Initially, pellets of PLA $(65 \mathrm{~g})$ were added into the mixer until totally melted. And then, PETA, DCP and TETDS were added into the mixer with the rotation speed of 60 rpm and reactive time of $6 \mathrm{~min}$. A contrasting experiment was carried out by 
adding only DCP and TETDS under the same processing conditions. The description of compositions is displayed in Table 1. Finally, the dried modified PLA $+0.4 \%$ PETA pellets were injection-moulded into samples with a range of injection speeds (300, 400500 and $600 \mathrm{~mm} / \mathrm{s}$ ) or corresponding volumetric flow rate $\left(5880,7840,9800\right.$ and $\left.11781 \mathrm{~mm}^{3} / \mathrm{s}\right)$ using a microinjection moulding machine (MicroPower5, Wittmann Battenfeld $\mathrm{GmbH}$, Austria) and miniinjection moulded samples using a mini-injection moulding machine (Thermo Scientific HAAKE Minijet, USA), respectively. The dimension of the microinjection moulded sample is $18 \times 3 \times 0.3 \mathrm{~mm}^{3}$ and the mini-injection moulded sample has dimensions of $78 \times 10 \times 4 \mathrm{~mm}^{3}$ (length $\times$ width $\times$ thickness). In this work, microinjection moulding was chosen for a comparison with mini-injection moulding. For microinjection moulding, injection speed is $600 \mathrm{~mm} / \mathrm{s}$, which corresponds to a volumetric flow rate of $11781 \mathrm{~mm}^{3} / \mathrm{s}$. The mini-injection moulding was purely pressure controlled at 500 Bar and volumetric flow rate is about $3.0 \times 10^{3} \mathrm{~mm}^{3} / \mathrm{s}$. The microinjection moulded and mini-injection moulded PLA (LCBPLA) samples were marked as micro-PLA (micro-LCBPLA) and mini-PLA (mini-LCBPLA), respectively.

Table 1 Formulations and sample names.

\begin{tabular}{ccccc}
\hline Samples & PLA $(\mathrm{g})$ & $\mathrm{DCP}(\mathrm{g})$ & $\mathrm{TETDS}(\mathrm{g})$ & $\begin{array}{c}\text { PETA( } \\
\mathrm{wt} \%)\end{array}$ \\
\hline Pure PLA & 65 & --- & --- & --- \\
PLA+0\%PETA & 65 & 0.04 & 0.18 & 0 \\
PLA+0.1\%PETA & 65 & 0.04 & 0.18 & 0.1 \\
PLA+0.2\%PETA & 65 & 0.04 & 0.18 & 0.2 \\
PLA+0.3\%PETA & 65 & 0.04 & 0.18 & 0.3 \\
PLA+0.4\%PETA & 65 & 0.04 & 0.18 & 0.4 \\
PLA+0.5\%PETA & 65 & 0.04 & 0.18 & 0.5 \\
PLA+1\%PETA & 65 & 0.04 & 0.18 & 1 \\
\hline
\end{tabular}


2.3 Gel permeation chromatography. Prior to testing, chloroform was used to dissolve all samples for $24 \mathrm{~h}$. Measurement of molecular weights of modified samples was carried on the SHIMADZU LC solution gel permeation chromatography (GPC). The test temperature was $40{ }^{\circ} \mathrm{C}$.

2.4 Differential Scanning Calorimetry (DSC). The crystallization morphologies were investigated by DSC. The type of DSC is TA-DSC Q20 (USA). Samples weighing about $5 \sim 8 \mathrm{mg}$ were heated to $200{ }^{\circ} \mathrm{C}$ to record melting curves. The heating rate is $10^{\circ} \mathrm{C} / \mathrm{min}$. Then, the samples were held at $200^{\circ} \mathrm{C}$ for $5 \mathrm{~min}$ before being cooled to $40{ }^{\circ} \mathrm{C}$ at $5{ }^{\circ} \mathrm{C} / \mathrm{min}$.

The relative crystallinity during the cooling process, $\mathrm{X}(\mathrm{T})$, can be expressed by Equation 1 as follows: ${ }^{22}$

$$
\mathrm{X}(\mathrm{T})=\frac{\int_{T_{0}}^{T}\left(\frac{d H}{d t}\right) d t}{\int_{T_{0}}^{T_{2}}\left(\frac{d H}{d t}\right) d t} \times 100 \%
$$

Where $d \mathrm{H} / \mathrm{dt}$ is the rate of heat-evolution, $\mathrm{T}_{\mathrm{o}}$ and $\mathrm{T}_{2}$ are the onset and end of crystallization temperatures, respectively. According to equation 1 and $t=\left(T_{0^{-}}\right.$ $\mathrm{T}) / \mathrm{R}$ (where $\mathrm{T}$ is the temperature at crystallization time $\mathrm{t}, \mathrm{R}$ is the cooling rate), the crystallization half-time, $t_{1 / 2}$, can be obtained.

Furthermore, the crystallinity $\left(\chi_{c}\right)$ of PLA during the melting process could be obtained using the following formula: ${ }^{23-24}$

$$
\chi_{c}=\frac{\Delta H_{m}-\Delta H_{C c}}{\Delta H_{0}} \times 100 \%
$$

where $\Delta H_{m}$ and $\Delta H_{c c}$ represent the melting enthalpy and the cold crystallization enthalpy of PLA, respectively. $\Delta H_{0}$ represents the complete crystallization enthalpy of PLA, which is $93 \mathrm{~J} \mathrm{~g}^{-1}$.

2.5 Polarizing Optical Microscope (POM). Optical observation of the crystalline morphologies of PLA (LCB-PLA) samples was investigated via an Olympus BX-51 optical microscope with a Linkam THMS 600 hot stage. The films were melted at 200 ${ }^{\circ} \mathrm{C}$ for $5 \mathrm{~min}$ before being cooled at $30{ }^{\circ} \mathrm{C} / \mathrm{min}$ to $140{ }^{\circ} \mathrm{C}$. And then held at 140 for 30 min to observe the spherulite growth.

2.6 Dynamic rheology measurements. For the study of linear rheological behaviours, the 2-mm-thinck plates were prepared by compression moulding at $180{ }^{\circ} \mathrm{C}$. Dynamic 
shear test was performed via a strain-controlled rheometer (ARES, TA Instruments) at $180{ }^{\circ} \mathrm{C}$ with frequency domain from 0.02 to $500 \mathrm{rad} / \mathrm{s}$.

A disc-like sample was also used to probe the influence of shear rate on the crystalline behaviour: The sample was melted at $180{ }^{\circ} \mathrm{C}$ for $5 \mathrm{~min}$, and then cooled to $150{ }^{\circ} \mathrm{C}$ at $15{ }^{\circ} \mathrm{C} / \mathrm{min}$. Subsequently the sample was cooled to $100{ }^{\circ} \mathrm{C}$ at various cooling rate of $0.4,0.6$, and $3{ }^{\circ} \mathrm{C} / \mathrm{min}$, respectively. During each process, the shear rate was kept at a constant shear rate about $0.05,0.1$ and $0.2 \mathrm{~s}^{-1}$, respectively. When the torque increased above $200 \mathrm{mN}$, the test was stopped.

Rectangular samples of $10 \mathrm{~mm}$ width and $17 \mathrm{~mm}$ length were made via compression moulding at $180{ }^{\circ} \mathrm{C}$. The uniaxial elongational viscosity at $170{ }^{\circ} \mathrm{C}$ was performed. During the process, the strain rates were held at $0.05,0.1,0.3$ and $0.5 \mathrm{~s}^{-1}$ respectively.

2.7 Synchrotron two-dimensional wide-angle X-ray diffraction (2D-WAXD). The orientation distribution and crystalline structure of samples were characterized by 2DWAXD (BL16B1, Shanghai Synchrotron Radiation Facility, China). The wavelength of X-ray is $0.124 \mathrm{~nm}$.

The orientation level of all samples can be quantitatively calculated by Herman's orientation factor $\left(f_{H}\right)$ :

$$
f_{H}=\frac{\left(3\left\langle\cos ^{2} \varphi\right\rangle-1\right)}{2}
$$

where $\cos ^{2} \varphi$ is an orientation factor defined as:

$$
\cos ^{2} \varphi=\frac{\int_{0}^{\pi / 2} \mathrm{I}(\theta) \sin \theta \cos ^{2} \theta \mathrm{d} \theta}{\int_{0}^{\pi / 2} \mathrm{I}(\theta) \sin \theta \mathrm{d} \theta}
$$

where $I(\theta)$ is the diffraction intensity at azimuthal angle $\theta$.

2.8 Mechanical properties measurement. Tensile strength measurements were curried out using a Testing Machine (Instron 5569) at $25^{\circ} \mathrm{C}$, with crosshead speed of $50 \mathrm{~mm} / \mathrm{min}$. The value of tensile strength was averaged over ten samples.

\section{Results And Discussion}

\subsection{Characterization of chain branched PLA}


3.1.1. Reaction in Haake and torque curves. Figure 1 illustrates a schematic representation of chain extension of PLA with PETA, TETDS and DCP. Here, it is relatively easy to create unstable free radicals (a) and more stable radicals (b), due to the low thermal stability of PLA. ${ }^{25}$ During the process, the grafted product (I) is obtained by reacting with free radicals (b), which is the main chemical reaction between PLA and DCP and forms the short chain structure. However, introducing PETA into the reaction system can induce a more complex reaction, resulting from the higher activity of $\mathrm{C}=\mathrm{C}$. During the reaction, both the complex and branched product ( II ) was generated. The reaction system represents a complex balance of degradation and chain extension.

The torque response of the reacting system is related to the apparent viscosity, which is affected by changes of chain structure of the polymer and can be recorded during the reaction. The formation of longer molecular chains or LCB in the reaction system can induce a dramatic increase of torque. As shown in Figure 2, a continuous decrease is initially observed, resulting from thermal and mechanical degradation during processing. At the beginning, simply introducing the DCP and TETDS into the reaction system was expected to generate branched PLA and it was expected that the torque reading would gradually increase as the branching increased. However, after the graft monomer is introduced into the reaction system, a second peak appears approximately 2 min after the melting peak. Moreover, increasing the PETA content can gradually increase the torque value, implying more branching reactions are occurring. In addition, increasing the content of PETA can clearly shorten the reaction time from $120 \mathrm{~s}$ to $80 \mathrm{~s}$, indicating that the reaction rate is accelerated by PETA.

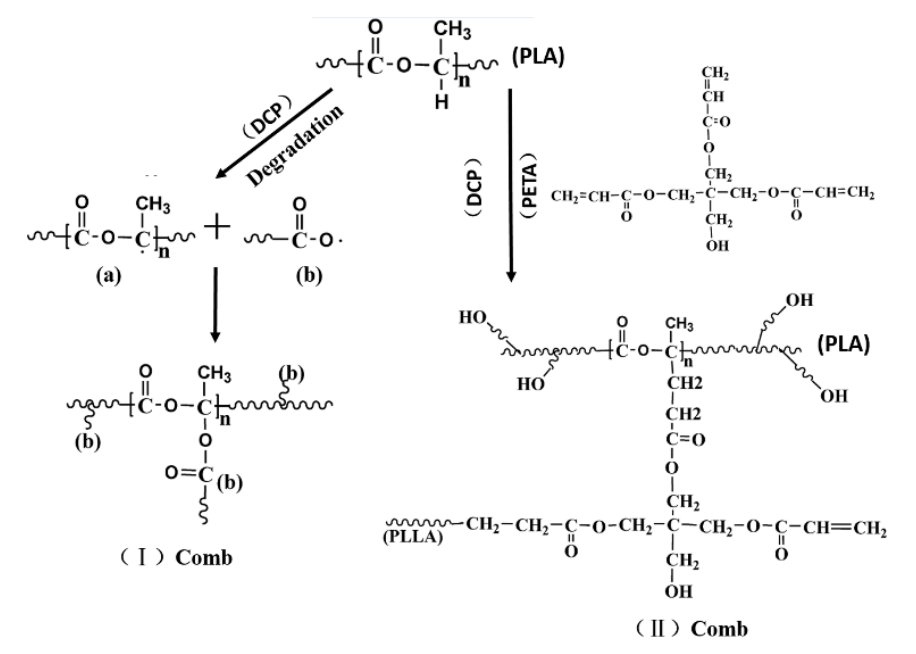


Figure 1 Schematic illustration of chemical reaction mechanism.

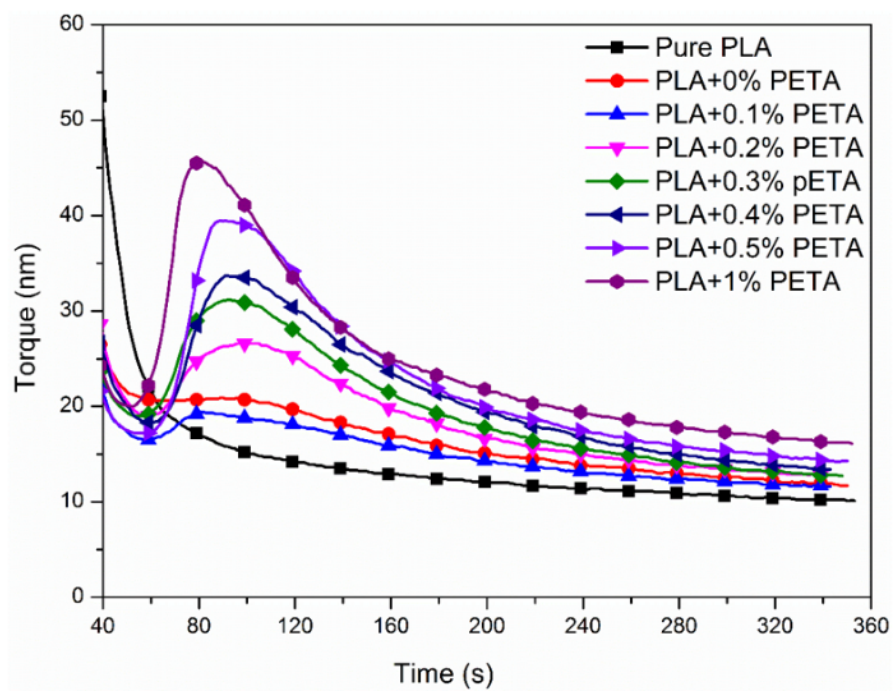

Figure 2 Torque evolution for all PLA sample reaction courses.

3.1.2. Linear rheology. In this study, dynamic rheological frequency sweeps were performed to observe the changes of complex viscosity $\left(\boldsymbol{\eta}^{*}\right)$, storage modulus $\left(\mathrm{G}^{\prime}\right)$, loss modulus $\left(\mathrm{G}^{\prime \prime}\right)$, and loss tangent $(\tan \boldsymbol{\delta})$. Figure 3a shows that complex viscosity of samples gradually increases with the increase of PETA content. However, the trend in complex viscosity become less distinct at the high frequencies. Furthermore, the PLA samples without the grafting monomer PETA exhibit a typical Newtonian behaviour and shear thinning behaviour, whereby complex viscosity is constant in the occurring in the low frequency region and then gradually decreases with increasing frequency. This phenomenon exhibits a transition from Newtonian plateau to the power law regime at the inflection point. With a further increase of PETA content (from $0.5 \mathrm{wt} \%$ to 1 $\mathrm{wt} \%$ ), the Newtonian behaviour cannot be discerned in the experimental frequency range, indicating the enhanced entanglement between PLA molecules. ${ }^{26}$

Figure $3 b$ shows the comparison of the loss tangent $\left(\tan \delta=\mathrm{G}^{\prime \prime} / \mathrm{G}^{\prime}\right)$ among the samples. For the pure PLA and LCB-PLA samples with less than $0.4 \mathrm{wt} \%$ PETA, $\tan \delta$ decreases and plateau cannot be discerned with the increase of frequency, exhibiting a liquid-like behaviour. ${ }^{27}$ The formation of LCB can change the terminal behaviour and the LCB-PLA samples demonstrate much less significant frequency dependency. In addition, with further increasing content of PETA, the plateau is eventually observed in the LCB-PLA samples with more than $0.4 \mathrm{wt} \%$ 
PETA, which demonstrated a gel-like behaviour. A similar gel-like behaviour was also observed in other LCB polymer materials. ${ }^{28-29}$ Furthermore, $\left(\mathrm{G}^{\prime}\right)$ and $\mathrm{G}^{\prime \prime}$ are both enhanced after chain branching (Figure $3 \mathrm{c}$ and $\mathrm{d}$ ). The degree of branching $(\chi)$ and zero-shear viscosity $\left(\eta_{0}\right)$ were calculated by Equation S1 and S4, ${ }^{26,30}$ as listed in Table 2 . With only adding the DCP and TETDS, the PLA $+0.1 \%$ PETA sample exhibits a lower degree of branching. However, the branching degree increases markedly from $3.7 \mathrm{~mol} \%$ to $49.5 \mathrm{~mol} \%$ with increasing the PETA content form $0.1 \mathrm{wt} \%$ to $1 \mathrm{wt} \%$, indicating that PETA content is highly significant for the LCB reaction.
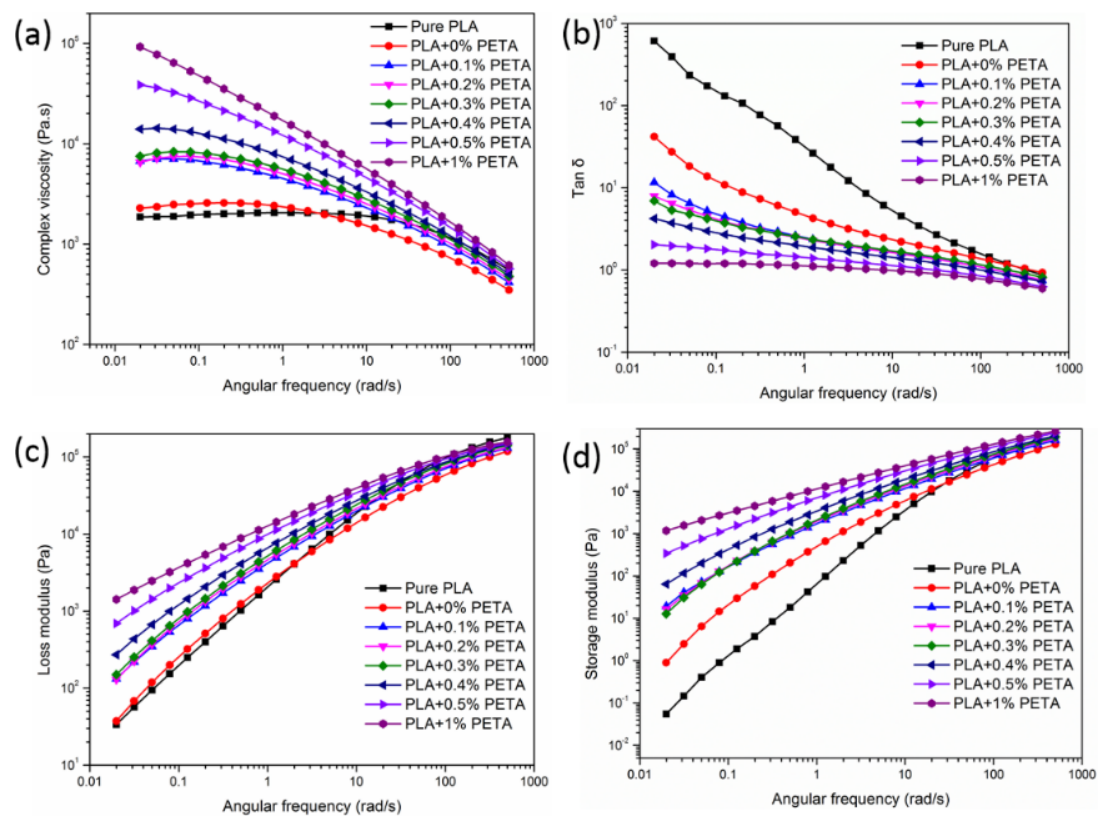

Figure 3 (a) complex viscosity $\left(\eta^{*}\right)$, (b) loss tangent (tan $\delta$ ), (c) loss modulus $\left(\mathrm{G}^{\prime \prime}\right)$ and $(d)$ storage modulus $\left(\mathrm{G}^{\prime}\right)$ as a function of measuring frequency $(\omega)$.

Table 2 The changes of the degree of branching and zero-shear viscosity.

\begin{tabular}{ccc}
\hline Samples & $\eta_{0}\left(10^{3}\right.$ Pa.s $)$ & $\boldsymbol{x}(\mathrm{mol} \%)$ \\
\hline Pure PLA & 2.0 & 0 \\
PLA+0\%PETA & 2.7 & 3.7 \\
PLA+0.1\%PETA & 7.8 & 16.8 \\
PLA+0.2\%PETA & 8.2 & 17.2 \\
PLA+0.3\%PETA & 8.7 & 17.8 \\
PLA+0.4\%PETA & 16 & 25.6 \\
\hline
\end{tabular}




$\begin{array}{ccc}\text { PLA }+0.5 \% \text { PETA } & 41 & 37.0 \\ \text { PLA }+1 \% \text { PETA } & 110 & 49.5\end{array}$

3.1.3. Uniaxial elongation. An ARES rheometer was utilized to examine the extensional flow characteristics of modified PLA by stretching in the molten state, in which the elongational viscosity is relative more sensitive to LCB than the shear rheology. In particular, the strain hardening behaviour can be observed with the increase in transient viscosity under certain strain, which can be used to characterise the formation of LCB. ${ }^{31-32}$ As shown in Figure 4, strain softening behaviour can be seen in the LCB-PLA samples with less than $0.1 \mathrm{wt} \%$ PETA, in which the transient elongational viscosity increases at the beginning of stretching and then decreases. This phenomenon is ascribed to lack of LCB in these samples. A similar behaviour was also found for long-chain branched poly (lactide) by $\boldsymbol{\gamma}$-radiation-induced chemical reactions. ${ }^{33}$ All other samples exhibit some degree of strain hardening, which requires the formation of a branched chain with more than two branching points. There is an absence of strain hardening in the PLA $+0.1 \%$ PETA sample which can be explained by the fact that it has short branched chains which does not contain as many entanglements as the other samples. Similar behaviour has also been observed in LCB-isotactic polypropylene (iPP) samples through electron beam irradiation induced long chain branched structure. ${ }^{34}$ Strain hardening behaviour can be clearly discerned for adding only $0.2 \mathrm{wt} \%$ PETA, due to forming the unique structure. As expected, at higher strain rates, earlier onset of strain hardening occurs. 


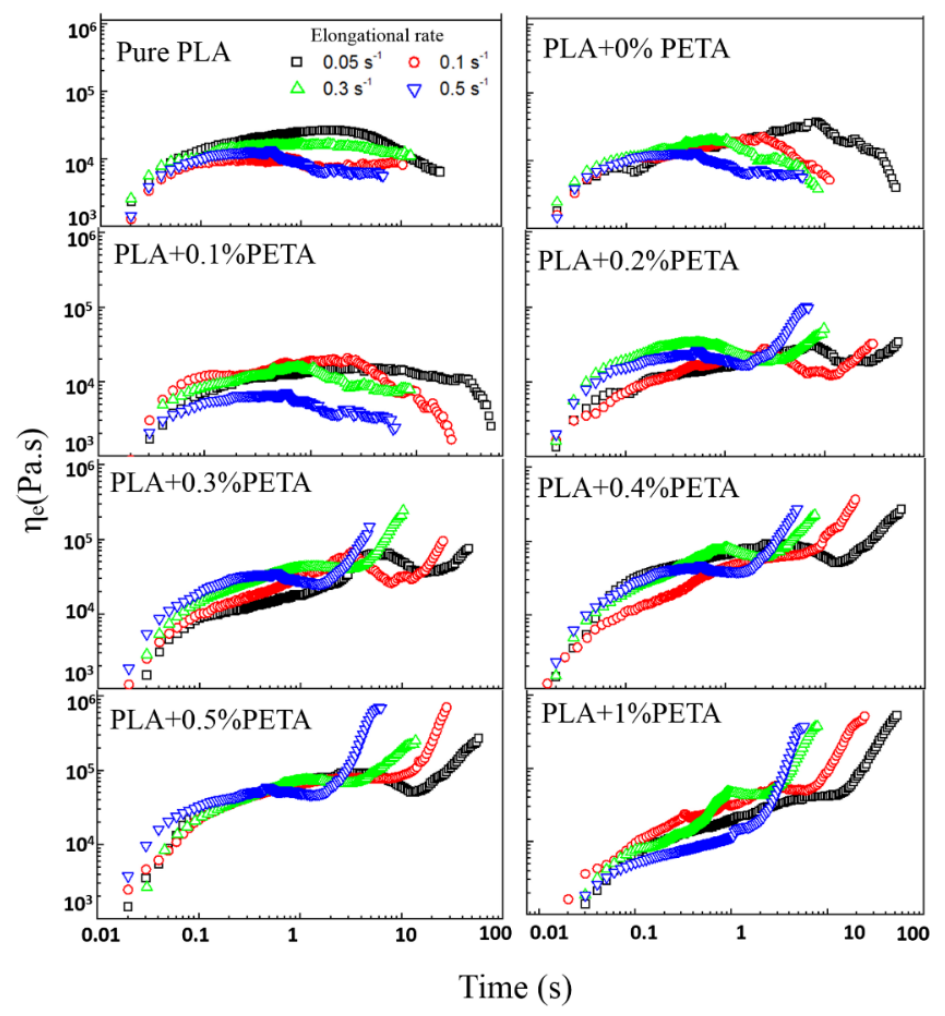

Figure 4 Elongational viscosity of PLA and modified PLA as a function of time at 170 ${ }^{\circ} \mathrm{C}$.

\subsection{Orientation structure and properties of microinjection mouldings}

3.2.1. The effect of LCB on the melt behaviours. The melting behaviour was examined by DSC to probe the influence of processing parameters on the crystalline behaviour during practical processing. As shown in Figure 5, three peaks are discerned in the DSC melting curves, which exhibit an enthalpy relaxation peak (glass transition, $\mathrm{T}_{\mathrm{g}}$ ), a cold crystallization exothermal peak $\left(\mathrm{T}_{\mathrm{c}}\right)$ and a melting endothermic peak $\left(\mathrm{T}_{\mathrm{m}}\right)$, respectively. During the heating process, the molecular chains can reorganize from from the amorphous to crystalline regions, leading to formation of a cold crystallization peak. ${ }^{35}$ As displayed in Figure 5a, the cold-crystallization peak temperature of LCBPLA samples decreases and could not be detected in mini-LCBPLA samples. The long chain branches play an important role in forming nucleation sites, markedly enhancing the nucleation ability of PLA during the cooling process. ${ }^{36-37}$ Meanwhile, introducing the LCB into PLA significantly decreases the melting point, due to the imperfect crystalline structure achieving from the faster cooling rate and the formation by 
degradation of relative short PLA molecular chains. Relative to mini-injection mouldings, a much sharper endothermic peak in the glass transition region is discerned, indicating that the microinjection mouldings show a stronger enthalpy relaxation. This phenomenon is due to the stronger shear stress and much higher temperature gradient under microinjection moulding conditions, promoting the physical aging process. ${ }^{3}$ The most striking difference among all samples is the crystallinity. As displayed in Table 3, the crystallinity of all PLA samples is less than $15 \%$, which is ascribed to the low crystallization capacity of PLA. However, the presence of LCB not only prohibits the cold crystallization process as seen from $\Delta \boldsymbol{H}_{\boldsymbol{c}}$ but also increases the crystallinity (Table 3) from about $13.3 \%$ to $41 \%$. Furthermore, increasing the injection speed (shear stress) can gradually increase the crystallinity from about $19.9 \%$ to $28.9 \%$. However, the LCBPLA mini-injection mouldings still have the highest crystallinity, resulting from the lower cooling rate and longer time to crystallize. These two factors (shear rate and cooling rate) significantly influence the crystalline behaviour during the injection moulding process. Generally, the maximum shear stress of microinjection moulding (about $2 \times 10^{6} \mathrm{~s}^{-1}$ ) can be two orders of magnitude higher than that in mini-injection moulding. ${ }^{21}$ Thus, typical shear stresses in microinjection moulding are much greater than those seen in mini-injection moulding. Moreover, the formation of LCB can provide an increased nucleation density during cooling from the melt, and prolong the relaxation time.

To have a deep understanding about the influence of cooling rate and shear stress on the crystalline behaviour, online rheological testing is used, as shown in Figure S1. As shown in Figure S1, increasing the shear rate and decreasing the cooling rate can raise the onset crystallization temperature. Hence, under the same process conditions, increasing the shear rate and introducing long chain branches promote to form nucleation sites and enhance crystallization kinetics, also verified using rotational rheometry and polarized optical microscopy. ${ }^{36-37}$ Hence, the competitive effect of shear rate and cooling rate is apparent. 

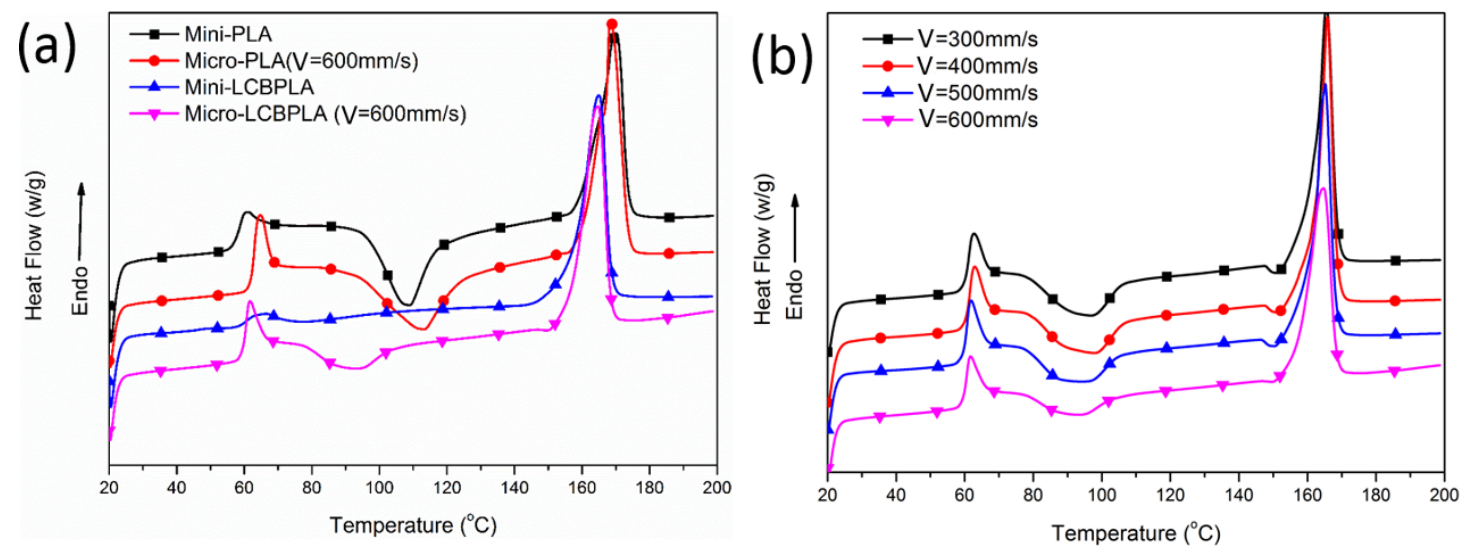

Figure 5 DSC melting curves of the samples at $10{ }^{\circ} \mathrm{C} / \mathrm{min}$. All the samples in the (b) are the micro-LCBPLA samples. ' $V$ ' represents the injection speed.

Table 3 The changes of cold crystallization enthalpy $\left(\Delta \mathrm{H}_{\mathrm{CC}}\right)$, melt enthalpy $\left(\Delta \mathrm{H}_{\mathrm{m}}\right)$ and the crystallinity $\left(\mathrm{X}_{\mathrm{c}}\right)$ in the samples.

\begin{tabular}{llll}
\hline \multicolumn{1}{c}{ Samples } & $\Delta \mathrm{H}_{\mathbf{c c}}(\mathrm{J} / \mathrm{g})$ & $\Delta \mathrm{H}_{\mathrm{m}}(\mathrm{J} / \mathrm{g})$ & $\mathrm{X}_{\mathbf{c}}(\%)$ \\
\hline Mini-PLA & 31.2 & 33.6 & 13.3 \\
Micro-PLA $(\mathrm{V}=600 \mathrm{~mm} / \mathrm{s})$ & 29.3 & 38.6 & 10.0 \\
Mini-LCBPLA & 0 & 38.4 & 41.0 \\
Micro-LCBPLA $(\mathrm{V}=600 \mathrm{~mm} / \mathrm{s})$ & 10.7 & 39.6 & 28.9 \\
Micro-LCBPLA $(\mathrm{V}=500 \mathrm{~mm} / \mathrm{s})$ & 20.2 & 40.1 & 21.4 \\
Micro-LCBPLA $(\mathrm{V}=400 \mathrm{~mm} / \mathrm{s})$ & 22.2 & 40.7 & 19.9 \\
Micro-LCBPLA $(\mathrm{V}=300 \mathrm{~mm} / \mathrm{s})$ & 21.5 & 41.3 & 21.3 \\
\hline
\end{tabular}

\subsubsection{Introduction of LCB and the prominent crystallization promoting effect.}

Based on the analysis above, forming the long chain branches can significantly enhance crystallinity and crystallization rate of PLA. To further probe the influence of forming the long chain branches, the crystallization behaviour was investigated systematically by DSC and POM. DSC cooling curves are exhibited in Figure 6 and the relative key parameters are presented in Table 4. Small exothermic peaks were observed in miniPLA sample during cooling process, probably because of the very low crystallization ability of PLA. However, when undergoing microinjection moulding, the crystallization rate is accelerated. This is because the long molecular chains may be broken into shorter chains resulting in the acceleration of movement and ordering of 
the PLA chains. With the addition of LCB, $T_{o}$ and $T_{p}$ for branched blends shift to a much higher temperature compared to that of standard PLA. In addition, increasing the shear rate can further enhance the $T_{o}$ and $T_{p}$. Specifically, $T_{p}$ of micro-PLA sample was $96.7^{\circ} \mathrm{C}$ while that of micro-LCBPLA sample sharply increased to $126.1^{\circ} \mathrm{C}$, showing a $29.4{ }^{\circ} \mathrm{C}$ change. Furthermore, the rate of crystallisation $\left(\boldsymbol{t}_{\mathbf{1 / 2}}\right)$ also significantly decreased from $2.78 \mathrm{~min}$ to $1.62 \mathrm{~min}$, showing the $1.16 \mathrm{~min}$ improvement. These results are ascribed to: The long chain branches can act as nucleating sites, enhancing the nucleation density and crystallization process. ${ }^{36-37}$
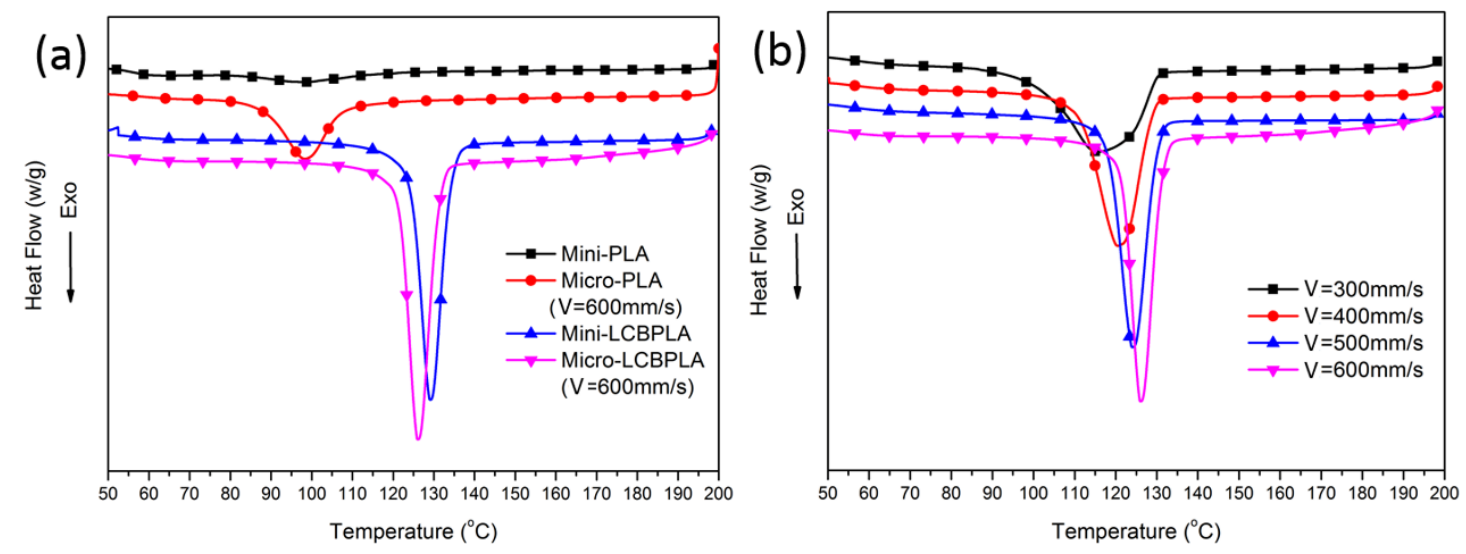

Figure 6 DSC cooling curves of samples at $5{ }^{\circ} \mathrm{C} / \mathrm{min}$. All the samples in the (b) are the micro-LCBPLA samples. ' $\mathrm{V}$ ' represents the injection speed.

Table 4 The changes of the onset crystallization temperature $\left(\mathrm{T}_{0}\right)$, peak crystallization temperature $\left(\mathrm{T}_{\mathrm{p}}\right)$ and the crystalline rate $\left(t_{1 / 2}\right)$ in all samples.

\begin{tabular}{llll}
\hline \multicolumn{1}{c}{ Samples } & $\mathrm{T}_{\mathrm{O}}\left({ }^{\circ} \mathrm{C}\right)$ & $\mathrm{T}_{\mathrm{P}}\left({ }^{\circ} \mathrm{C}\right)$ & $\mathrm{T}_{0.5}(\mathrm{~min})$ \\
\hline Micro-PLA $(\mathrm{V}=600 \mathrm{~mm} / \mathrm{s})$ & 110.6 & 96.7 & 2.78 \\
Mini-LCBPLA & 137.4 & 127.2 & 2.08 \\
Micro-LCBPLA $(\mathrm{V}=600 \mathrm{~mm} / \mathrm{s})$ & 135.3 & 126.1 & 1.62 \\
Micro-LCBPLA $(\mathrm{V}=500 \mathrm{~mm} / \mathrm{s})$ & 134.1 & 124.1 & 1.74 \\
Micro-LCBPLA $(\mathrm{V}=400 \mathrm{~mm} / \mathrm{s})$ & 132.2 & 120.5 & 1.81 \\
Micro-LCBPLA $(\mathrm{V}=300 \mathrm{~mm} / \mathrm{s})$ & 131.7 & 115.6 & 2.20 \\
\hline
\end{tabular}

Nucleation and crystal growth are two main parts of crystallization process, which would affect the total crystallization rate. As shown in Table $4, t_{1 / 2}$ for branched samples is lower than that of the neat PLA sample. However, simply using $\mathrm{t}_{1 / 2}$ cannot adequately characterize non-isothermal crystallization rate, 
because the nucleation occurs at the early stage during the crystallization process but crystal growth dominates at the later stage. Therefore, non-isothermal crystallization rate constant $\left(\mathrm{Z}_{\mathrm{c}}\right)$ of the micro-PLA and micro-LCBPLA were $8 \times 10^{-3}$ and $3 \times 10^{-2}$, respectively (seen Figure S2). This result shows that LCB increases the density of nucleation sites and the activation energy of nucleation, so long chain branches serve as nucleating agents which accelerate the nucleation process. Secondly, the long molecular chains can be broken, because of the extreme shear rates. Figure S3 shows the GPC curves of LCB-PLA samples and different injection moulding conditions. This highlights that, compared with mini-injection moulding, the increased shear stress and shear strain rate in microinjection moulding can induce the breakage of the long molecular chains, and narrow the polydispersity. Hence, the formation of LCB and the application of extreme shear rate can accelerate the crystalline rate and promote the crystallization process.

POM measurements provide further evidence for this promoting effect. As shown in Figure 7a, at isothermal crystallization temperatures of $140{ }^{\circ} \mathrm{C}$, no heat flow peak is observed for micro-PLA sample, indicating that PLA cannot crystallize at such high temperature in the whole crystallization time. However, there is obvious evidence verifying the existence of heat flow peak in microLCBPLA samples. Meanwhile, the crystallization peak becomes sharpened and the crystallization time shortens rapidly, and completing the whole crystallization process needs about $3 \mathrm{~min}$. These results powerfully attest the remarkable effect of LCB in promoting crystallization. The promotion effect of crystal nucleation is investigated by $\mathrm{POM}$ at $140{ }^{\circ} \mathrm{C}$, as displayed in Figure $7 \mathrm{~b}$. As expected, introducing the LCB can significantly accelerate the formation of nuclei in a relatively short time (about $3 \mathrm{~min}$ at $140{ }^{\circ} \mathrm{C}$ ) and shorten the whole crystallization process (about $10 \mathrm{~min}$ at $140{ }^{\circ} \mathrm{C}$ ), resulting in the appearance of many smallsized spherulites in the final period. These results reveal that the incorporation of LCB can remarkably accelerate the nucleation process of PLA by improving the nucleation density. In contrast to the previous reports, ${ }^{36-39}$ the promotion effect is clearer, with short crystallization times and small size of spherulites. 

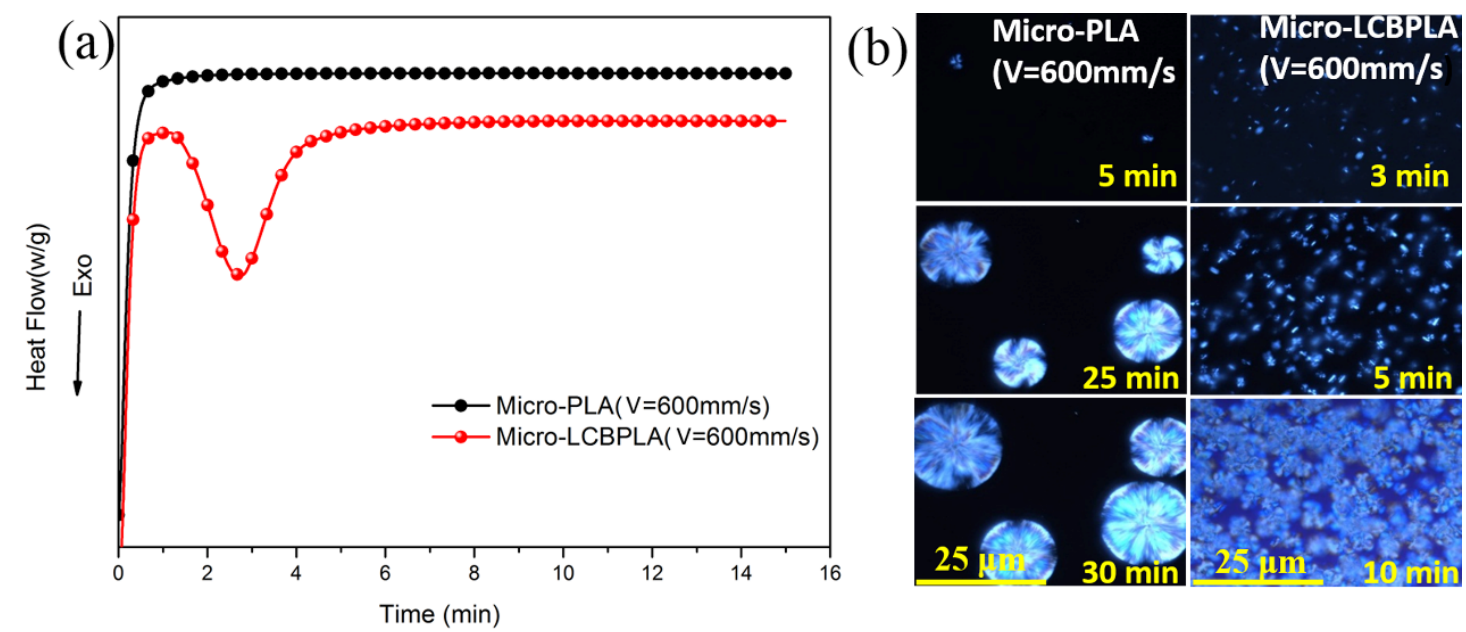

Figure 7 (a) DSC heating flow as a function of time and (b) selected POM micrographs. The isothermal crystallization of samples was followed at $140{ }^{\circ} \mathrm{C}$.

3.2.3. Orientation property. Figure 8 displays the WAXD patterns of samples, which reflects the changes in crystallization structure and orientation distribution of samples due to LCB for various processing conditions. The $(200) /(110)$ reflection pattern presented two strong circular spots, indicating that intensive molecular orientation. Compared to those of mini-injection mouldings, the diffraction patterns of microinjection mouldings present more sharp arcs, indicating the intensive molecular chain orientation in these samples. The degree of orientation can be obtained by Equations 3 and 4. The relative results are shown in Table 5. For the PLA samples, the orientation degree increased from 0.54 to 0.86 after applying the extreme shear rate. The formation of branched PLA can also further raise the orientation degree from 0.86 to 0.91 . This is due to the formation of LCB promoting the preservation of oriented molecular chains. ${ }^{29}$ According to previous reports, ${ }^{40-41}$ when polymer molecules are above a "critical orientation molecular weight" $\left(\mathbf{M}^{*}\right)$, the polymer molecular chains may become oriented along the flow direction under shear stress. Moreover, the molecular relaxation of oriented clusters will occur under a high temperature environment. During microinjection, the molecular chains tend to highly orient along the shear direction, due to the higher shear stress and faster cooling rate. The faster cooling rate and forming long chain branches retard the relaxation of oriented molecular chains, leading to high orientation degree. Changing the injection speed from $400 \mathrm{~mm} / \mathrm{s}$ to $600 \mathrm{~mm} / \mathrm{s}$, the orientation degree has less changes, indicating the effect of shear stress may have reached a limit. 
Figure $8 \mathrm{i}$ and $\mathrm{j}$ show the 1D-WAXD diffraction curves integrated from the corresponding WAXD patterns. The polymorphism of PLA exists in the injection moulded samples, especially in LCB-PLA samples. The diffraction peaks of $\alpha-$ form of PLA at $2 \theta=15.1,16.7,18.3$ and $22.4^{\circ}$, corresponding to (010), (200)/(110), (203), and (210) planes, are observed, respectively. ${ }^{42}$ A weak diffraction peak at $2 \theta \approx 29.1^{\circ}$ was also observed in the branched samples, which could be assigned to the crystal planes (003) of the $\beta$ crystal form of PLA. The results indicate that introducing the LCB into PLA matrix can promote the crystal transformation from $\alpha$ to $\beta$ crystal forms. Moreover, Figure $8 \mathrm{j}$ shows that no clear $(003)_{\beta}$ reflection was distinguished from the intensity distribution at low injection speeds, providing no evidence for forming $\beta$ crystals. However, the intensity of the $(003)_{\beta}$ reflection increased with increasing injection speeds, indicating that the cooling rate and the shear flow field play a significant role in forming the $\beta$-crystal form.

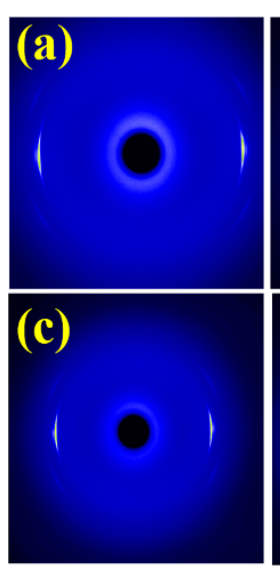

(i)

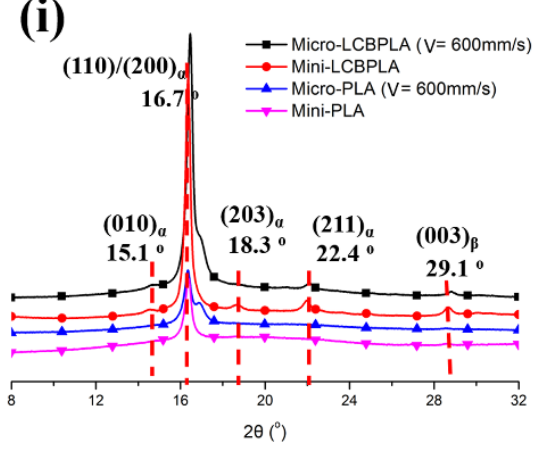

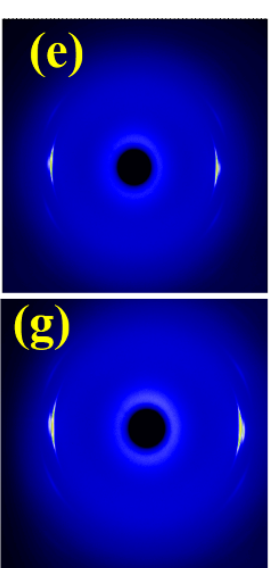

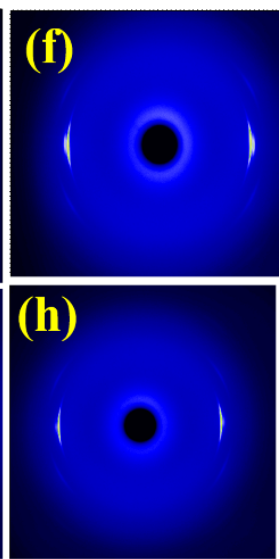

(j)

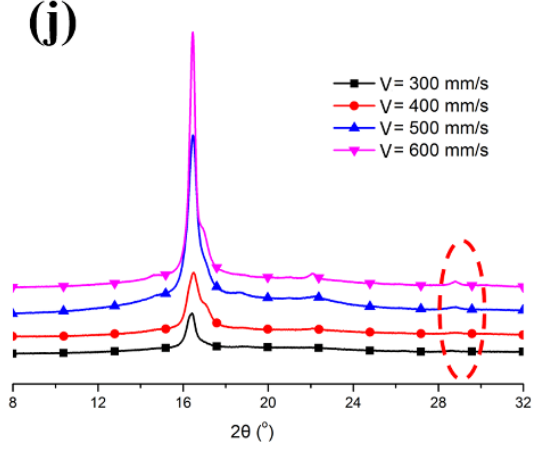


Figure 8 Typically selected WAXD patterns: (a) Micro-PLA (V=600mm $/ \mathrm{s})$, (b) Mini-PLA, (c) Micro-LCBPLA (V=600mm/s), (d) Mini-LCBPLA, (e) $\mathrm{V}=300 \mathrm{~mm} / \mathrm{s}$, (f) $\mathrm{V}=400 \mathrm{~mm} / \mathrm{s},(\mathrm{g}) \mathrm{V}=500 \mathrm{~mm} / \mathrm{s}$ and (h) $\mathrm{V}=600 \mathrm{~mm} / \mathrm{s}$. (i) and (j): 1D-WAXD intensity profiles of samples. All the samples in the $(j)$ are the microLCBPLA samples. ' $\mathrm{V}$ ' represents the injection speed.

Table 5 Orientation degree fitted from the intensities along the azimuthal angle.

\begin{tabular}{cc}
\hline Samples & Orientation degree $\left(f_{H}\right)$ \\
\hline Mini-PLA & 0.54 \\
Micro-PLA $(\mathrm{V}=600 \mathrm{~mm} / \mathrm{s})$ & 0.86 \\
Mini-LCBPLA & 0.73 \\
Micro-LCBPLA $(\mathrm{V}=600 \mathrm{~mm} / \mathrm{s})$ & 0.91 \\
Micro-LCBPLA $(\mathrm{V}=500 \mathrm{~mm} / \mathrm{s})$ & 0.90 \\
Micro-LCBPLA $(\mathrm{V}=400 \mathrm{~mm} / \mathrm{s})$ & 0.89 \\
Micro-LCBPLA $(\mathrm{V}=300 \mathrm{~mm} / \mathrm{s})$ & 0.88 \\
\hline
\end{tabular}

3.2.4. Mechanical properties. Changes in tensile strength of all the samples are displayed in Figure 9. Introducing the LCB into the PLA matrix considerably increases the tensile strength from 53.8 $\mathrm{MPa}$ to $74.3 \mathrm{MPa}$. In contrast to previous work, ${ }^{43}$ microinjection moulded samples have an increased tensile strength from $74.3 \mathrm{MPa}$ to 98.4 MPa. Moreover, increasing the injection speed can also raise the tensile strength. Based on the theory of polymer strength, ${ }^{44-45}$ the formation of entanglement among long chain branches can increase the molecular chains interaction and hinder the molecular slippage. ${ }^{46}$ As described previously, the formation of long chain branches is beneficial to entangle and form the framework structure (Figure 3), which would be beneficial to raise the tensile strength of LCB-PLA samples. As can be seen from Figure 10, for liner PLA samples, the breakage and slippage of molecules can induce the fracture of chemical bonds and Van der Waals forces after applying the stress. However, aside from that in LCB-PLA samples, the disentanglements and breakage of long chain branches can also induce the fracture. In addition, the crystalline structures (spherulite size) and the oriented molecules are also important factors affecting the tensile strength of polymers. The higher crystalline temperature and nucleation rate promoted is beneficial to form amount of small spherulities (Figure 7) and prolonged the relaxation 
time, which can promote the reservation of orientation structures under microinjection moulding (Figure 8).

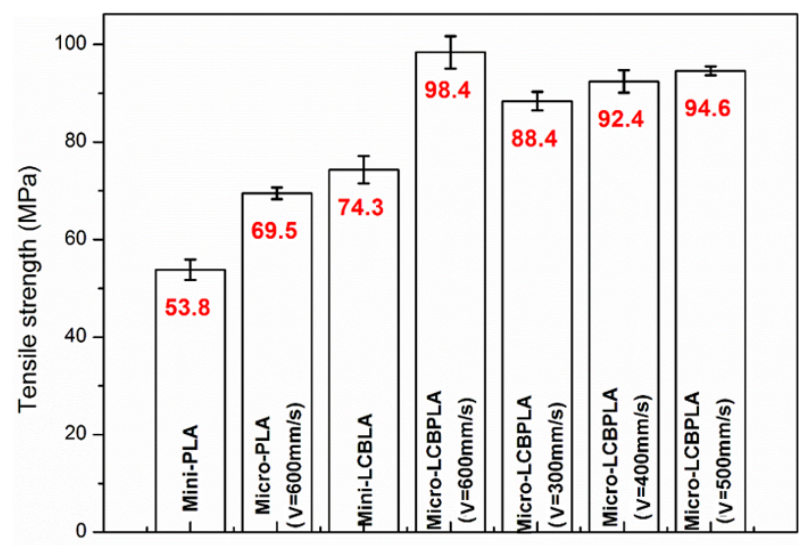

Figure 9 Tensile strength of samples. 'V' represents the injection speed.

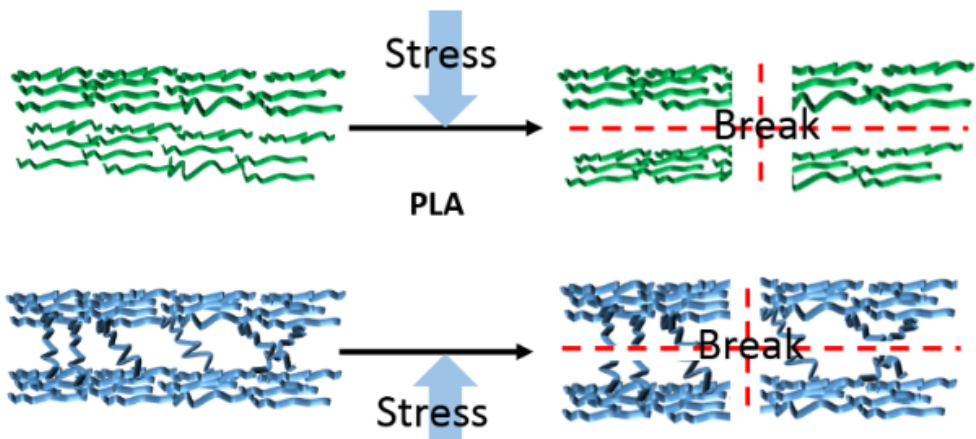

LCBPLA

Figure 10 Fracture schematic representation of PLA and LCB-PLA samples.

\section{Conclusions}

In this study, a high degree of long chain branched PLA was prepared by melt radical reaction with PETA, TETDS and DCP. Rheological and GPC analyses illustrated that introducing the PETA into the reactive system promoted to form the branched structure, in which a degree of branching as high as $49.5 \mathrm{~mol} \%$ could be achieved by adding only $1 \mathrm{wt} \%$ PETA monomer. In addition, strain hardening occurs with adding only $0.2 \mathrm{wt} \%$ PETA. The formation of LCB can significantly improve the crystalline rate in nonisothermal and isothermal experiments, in which the cold crystallization cannot be discerned in the miniinjection mouldings. Further studies show that the half crystallization time during 
the non-isothermal crystallization process (cooling rate: $5{ }^{\circ} \mathrm{C} / \mathrm{min}$ ) decreases substantially in LCBPLA samples from $3 \mathrm{~min}$ to $1.5 \mathrm{~min}$. Furthermore, forming LCB can also significantly raise the orientation degree, especially in LCB-PLA microinjection mouldings and promote the crystalline transformation from $\alpha$ to $\beta$-crystal forms. Increasing the injection speed is beneficial to form the $\beta$-crystals and further raise the mechanical properties. Combining the LCB and the shear stress can significantly raise the tensile strength by $\sim 45 \mathrm{MPa}$. Therefore, introducing PETA into the reactive system not only increased branching degree, promoted tensile strength, especially microinjection mouldings, but also enhanced the crystallization capacity.

\section{ASSOCIATED CONTENT}

\section{Supporting Information}

The related supplementary data are displayed.

\section{Notes}

The authors declare no competing financial interest.

\section{ACKNOWLEDGEMENTS}

The authors express great thanks to the Foundation for Innovative Research Groups of the National Natural Science Foundation of China (Grant 51721091), the Program of Introducing Talents of Discipline to Universities (Grant B13040) and the Scientific Research Foundation of International Cooperation and Exchanges of Sichuan Province (Grant No.2017HH0003). We are indebted to the Shanghai Synchrotron Radiation Facility (SSRF) for WAXD experiments.

\section{REFERENCES}

(1) Heckele, M.; Schomburg, W. K. Review on micro molding of thermoplastic polymers. J. Micromech. Microeng. 2003, 14, R1.

(2) Li, M. J.; Qi, Y.; Zhao, Z. Z.; Xiang, Z.; Liao, X.; Niu, Y. H.; Kong, M. Q. Morphology evolution and crystalline structure of controlled-rheology polypropylene in micro-injection molding. Polym. Advan. Technol. 2015, 4, 494-503. 
(3) Liu, Z.; Chen, Y. H.; Ding, W. W.; Zhang, C. H. Filling behavior, morphology evolution and crystallization behavior of microinjection molded poly (lactic acid)/hydroxyapatite nanocomposites. Compos. Part A-Appl. Sci. Manuf. 2015, 72, 8595.

(4) Shao, J.; Xiang, S.; Bian, X. C.; Sun, J. R.; Li, G.; Chen, X. S. Remarkable Melting Behavior of PLA Stereocomplex in Linear PLLA/PDLA Blends. Ind. Eng. Chem. Res. 2015, 54, 2246-2253.

(5) Xu, H.; Xie, L.; Chen, Y. H.; Huang, H. D.; Xu, J. Z.; Zhong, G. J.; Hsiao, B. S.;

Li, Z. M. Strong Shear Flow-Driven Simultaneous Formation of Classic Shish-Kebab, Hybrid Shish-Kebab, and Transcrystallinity in Poly(lactic acid)/Natural Fiber Biocomposites. ACS. Sustain. Chem. Eng. 2013, 1, 1619-1629.

(6) Day, M.; Nawaby, A.; Liao, X. A DSC study of the crystallization behaviour of polylactic acid and its nanocomposites. J. Therm. Anal. Calorim. 2006, 86, 623-629.

(7) Kaczmarek, H.; Nowicki, M.; Vuković-Kwiatkowska, I.; Nowakowska, S. Crosslinked blends of poly (lactic acid) and polyacrylates: AFM, DSC and XRD studies. J. Polym. Res. 2013, 20, 91-103.

(8) Zhou, H.; Touny, A. H.; Bhaduri, S. B. Fabrication of novel PLA/CDHA bionanocomposite fibers for tissue engineering applications via electrospinning. $J$. Mater. Sci-Mater. Med. 2011, 22, 1183-1193.

(9) Dorgan, J. R.; Janzen, J.; Clayton, M. P.; Hait, S. B.; Knauss, D. M. Melt rheology of variable L-content poly (lactic acid). J.Rheol. 2005, 49, 607-619.

(10) Palade, L. I.; Lehermeier, H. J.; Dorgan, J. R. Melt rheology of high L-content poly (lactic acid). Macromolecules 2001, 34, 1384-1390.

(11) Yu, L.; Dean, K.; Li, L. Polymer blends and composites from renewable resources. Prog. Polym. Sci. 2006, 31, 576-602.

(12) Baratian, S.; Hall, E. S.; Lin, J. S.; Xu, R.; Runt, J. Crystallization and solid-state structure of random polylactide copolymers: poly (l-lactide-co-d-lactide) s. Macromolecules 2001, 34, 4857-4864.

(13) Xu, H.; Teng, C. Q.; Yu, M. H. Improvements of thermal property and crystallization behavior of PLLA based multiblock copolymer by forming stereocomplex with PDLA oligomer. Polymer 2006, 47, 3922-3928.

(14) Martin, O.; Averous, L. Poly (lactic acid): plasticization and properties of biodegradable multiphase systems. Polymer 2001, 42, 6209-6219. 
(15) Xiao, H. W.; Lu, W.; Yeh, J. T. Effect of plasticizer on the crystallization behavior of poly (lactic acid). J. Appli. Polym.Sci. 2009, 113, 112-121.

(16) Liao, R. G.; Yang, B.; Yu, W.; Zhou, C. X. Isothermal cold crystallization kinetics of polylactide/nucleating agents. J. Appli. Polym. Sci. 2007, 104, 310-317.

(17) Schmidt, S. C.; Hillmyer, M. A. Polylactide stereocomplex crystallites as nucleating agents for isotactic polylactide. J. Polym. Scie. Part-Polym. Phys. 2001, 39, 300-313.

(18) Liu, J. Y.; Lou, L. J.; Yu, W.; Liao, R. G.; Li, R. M.; Zhou, C. X. Long chain branching polylactide: Structures and properties. Polymer 2010, 51, 5186-5197.

(19) Li, Z. Q.; Zhao, X. W.; Lin, Y.; Coates, P.; Caton-Rose, F.; Martyn, M. Structure and blood compatibility of highly oriented poly( 1 -lactic acid) chain extended by ethylene glycol diglycidyl ether. Polymer 2015, 56, 523-534.

(20) You, J. X.; Lou, L. J.; Yu, W.; Zhou, C. X. The preparation and crystallization of long chain branching polylactide made by melt radicals reaction. J. Appli. Polym. Sci. 2013, 129, 1959-1970.

(21) Zhao, Z. Z.; Yang, Q.; Gong, P. J.; Sun, H. W.; Wu, P. P.; Huang, Y. J.; Liao, X. Effects of Process Temperatures on the Flow-Induced Crystallization of Isotactic Polypropylene/Poly (ethylene terephthalate) Blends in Microinjection Molding. Ind. Eng. Chem. Res. 2017, 56, 9467-9477.

(22) Zhong, G. J.; Li, Z. M.; Li, L. B.; Shen, K. Z. Crystallization of oriented isotactic polypropylene (iPP) in the presence of in situ poly (ethylene terephthalate)(PET) microfibrils. Polymer 2008, 49, 4271-4278.

(23) Harris, A. M.; Lee, E. C. Improving mechanical performance of injection molded PLA by controlling crystallinity. J. Appli. Polym. Sci. 2008, 107, 2246-2255.

(24) Yin, H. Y.; Wei, X. F.; Bao, R. Y.; Dong, Q. X.; Liu, Z. Y.; Yang, W.; Xie, B. H.; Yang, M. B. Enhancing thermomechanical properties and heat distortion resistance of poly (L-lactide) with high crystallinity under high cooling rate. ACS. Sustain. Chem. Eng. 2015, 3, 654-661.

(25) Babanalbandi, A.; Hill, D. J. T.; O'Donnell, J. H.; Pomery, P. J.; Whittaker, A. An electron spin resonance study on $\gamma$-irradiated poly (1-lactic acid) and poly (d, 1-lactic acid). Poly. Degrad. Stabil. 1995, 50, 297-304. 
(26) Fang, H. G.; Zhang, Y. Q.; Bai, J.; Wang, Z. K.; Wang, Z. G. Bimodal architecture and rheological and foaming properties for gamma-irradiated long-chain branched polylactides. $R S C A d v$. 2013, 3, 8783-8795.

(27) Li, Z. Q.; Zhao, X. W.; Ye, L.; Coates, P.; Caton-Rose, F.; Martyn, M. Fibrillation of Chain branched Poly (lactic acid) with Improved Blood Compatibility and Bionic Structure. Chem. Eng. J. 2015, 279, 767-776.

(28) García-Franco, C. A.; Srinivas, S.; Lohse, D. J.; Brant, P. Similarities between gelation and long chain branching viscoelastic behavior. Macromolecules 2001, 34, 3115-3117.

(29) Li, S. Z.; Xiao, M. M.; Wei, D. F.; Xiao, H. N.; Hu, F. Z.; Zheng, A. The melt grafting preparation and rheological characterization of long chain branching polypropylene. Polymer 2009, 50, 6121-6128.

(30) Wang, Y. B.; Yang, L.; Niu, Y. H.; Wang, Z. G.; Zhang, J.; Yu, F. Y.; Zhang, H. B. Rheological and topological characterizations of electron beam irradiation prepared long - chain branched polylactic acid. J.Appli. Polym. Sci. 2011, 122, 1857-1865.

(31) Shabbir, A.; Huang, Q.; Baeza, G. P.; Vlassopoulos, D.; Chen, Q.; Colby, R. H.; Alvarez, N. J.; Hassager, O. Nonlinear shear and uniaxial extensional rheology of polyether-ester-sulfonate copolymer ionomer melts. J. Rheol. 2017, 61, 1279-1289.

(32) Stange, J.; Uhl, C.; Münstedt, H. Rheological behavior of blends from a linear and a long-chain branched polypropylene. J. Rheol. 2005, 49, 1059-1079.

(33) Xu, H. J.; Fang, H. G.; Bai, J.; Zhang, Y. Q.; Wang, Z. G. Preparation and characterization of high-melt-strength polylactide with long-chain branched structure through $\gamma$-radiation-induced chemical reactions. Ind. Eng. Chem. Res. 2014, 53, 11501159.

(34) Auhl, D.; Stange, J.; Münstedt, H.; Krause, B.; Voigt, D.; Lederer, A.; Lappan, U.; Lunkwitz, K. Long-chain branched polypropylenes by electron beam irradiation and their rheological properties. Macromolecules 2004, 37, 9465-9472.

(35) Jandas, P. J.; Mohanty, S.; Nayak, S. K. Thermal properties and cold crystallization kinetics of surface-treated banana fiber (BF)-reinforced poly(lactic acid) (PLA) nanocomposites. J. Therm. Anal. Calorim. 2013, 114, 1265-1278.

(36) Bai, J.; Fang, H. G.; Zhang, Y. Q.; Wang, Z. G. Studies on crystallization kinetics of bimodal long chain branched polylactides. Cryst. Eng. Comm 2014, 16, 2452-2461. 
(37) Fang, H. G.; Zhang, Y. Q.; Bai, J.; Wang, Z. G. Shear-induced nucleation and morphological evolution for bimodal long chain branched polylactide. Macromolecules 2013, 46, 6555-6565.

(38) Nofar, M.; Zhu, W. L.; Park, C. B.; Randall, J. Crystallization kinetics of linear and long-chain-branched polylactide. Ind. Eng. Chem. Res. 2011, 50, 13789-13798.

(39) Wang, L. Y.; Jing, X. B.; Cheng, H. B.; Hu, X. L.; Yang, L. X.; Huang, Y. B. Rheology and crystallization of long-chain branched poly (L-lactide) s with controlled branch length. Ind. Eng. Chem. Res. 2012, 51, 10731-10741.

(40) Chen, Y. H.; Zhong, G. J.; Lei, J.; Li, Z. M.; Hsiao, B. S. In situ synchrotron Xray scattering study on isotactic polypropylene crystallization under the coexistence of shear flow and carbon nanotubes. Macromolecules 2011, 44, 8080-8092.

(41) Yang, L.; Somani, R. H.; Sics, I.; Hsiao, B. S.; Kolb, R.; Fruitwala, H.; Ong, C. Shear-induced crystallization precursor studies in model polyethylene blends by in-situ rheo-SAXS and rheo-WAXD. Macromolecules 2004, 37, 4845-4859.

(42) Zhang, J. M.; Duan, Y.; Sato, H.; Tsuji, H.; Noda, I.; Yan, S.; Ozaki, Y. Crystal modifications and thermal behavior of poly (L-lactic acid) revealed by infrared spectroscopy. Macromolecules 2005, 38, 8012-8021.

(43) Xie, L.; Sun, X.; Tian, Y. Z.; Dong, F. P.; He, M.; Xiong, Y. Z.; Zheng, Q. Selfnanofibrillation strategy to an unusual combination of strength and toughness for poly(lactic acid). $R S C A d v .2017,7,11373-11380$.

(44) Deng, S. W.; Zhao, X. Z.; Huang, Y. M.; Han, X.; Liu, H. L.; Hu, Y. Deformation and fracture of polystyrene/polypropylene blends: a simulation study. Polymer 2011, 52, 5681-5694.

(45) Wang, J.; Liu, R. H.; Yu, P.; Tang, A. K.; Xu, L.; Wang, J. Y. Study on the pollution characteristics of heavy metals in seawater of Jinzhou Bay. Pro. Envi. Sci. 2012, 13, 1507-1516.

(46) Zhao, W. Y.; Huang, Y. J.; Liao, X.; Yang, Q. The molecular structure characteristics of long chain branched polypropylene and its effects on non-isothermal crystallization and mechanical properties. Polymer 2013, 54, 1455-1462. 

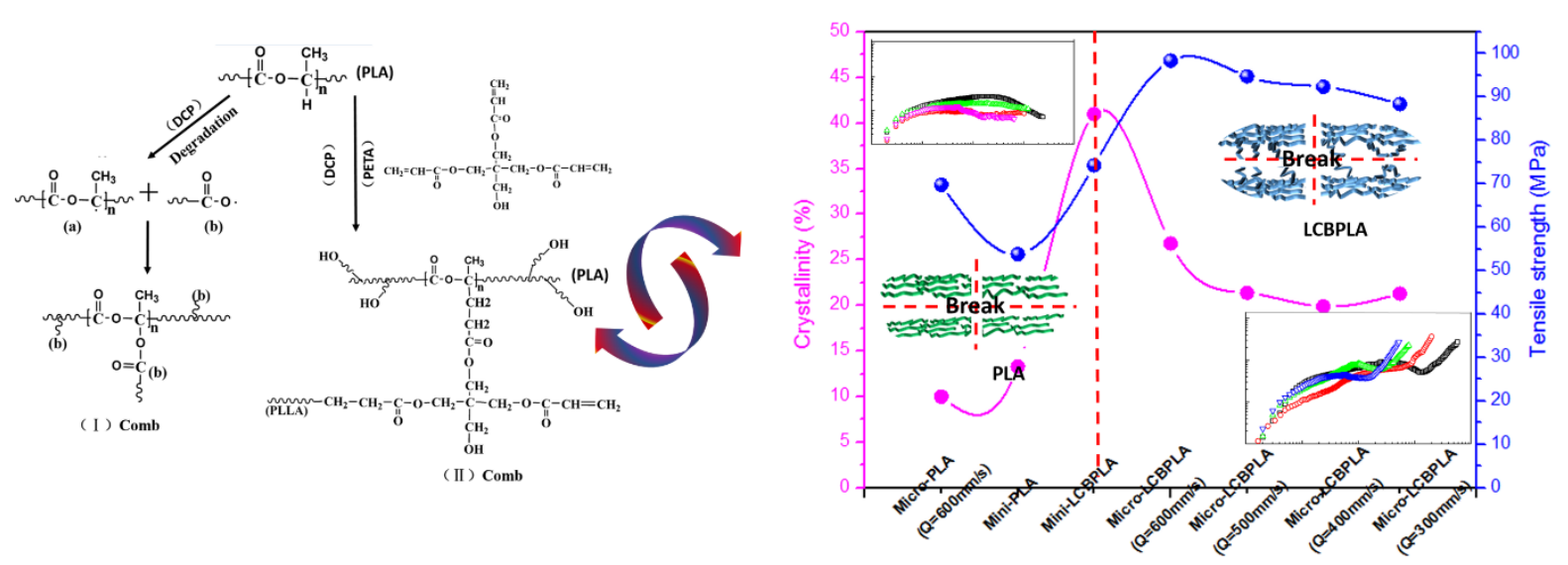

Combining of physical and chemical modifications was utilized to systemically improve the crystallization and mechanical properties of poly (lactic acid) 